\title{
Frequency of Mandibular 3rd Molar Presence and Position on Risk of Mandibular Angle Fracture
}

\author{
Nizam Khan Ghaffari ${ }^{1} \quad$ Saima Munir ${ }^{2} \quad$ Noorul Ain Arshad ${ }^{2} \quad$ Zia Uddin $^{3}$ Sohail Fareed ${ }^{2}$ \\ Khalil Ahmad Khan ${ }^{2}$ \\ 1.Bakhtawar Amin Medical and Dental College, Multan \\ 2.Nishtar Institute of Dentistry, Multan \\ 3.Dental Surgeon Civil Hospital Kabal Swat.
}

\begin{abstract}
Objective of study was to determine the frequency of mandibular third molar presence and position in mandibular angle fractures. Study Design: Cross Sectional Study Setting: This study was carried out in department of dentistry, Nishtar institute of dentistry, Multan. Duration of Study: This study was conducted from $1^{\text {st }}$ July 2016 to $31^{\text {st }}$ January 2017. Methadology: Study was started after taking informed consent from the patients and approval of ethical committee. Fracture side was diagnosed by history and examination. Status of mandibular third molar (erupted, un-erupted and impacted) on the side of fracture was evaluated through clinical and radio-graphical examination. Data was collected for basic demographics (Age, Sex and side of fracture).Patients from both gender with age range of 25-40 years having mandibular angle fracture of any side of $<$ one month duration were included in this study. Patients with history of extraction of mandibular third molar and those with history of fracture from gunshot injury were excluded from the study.Data was collected for mandibular third molar presence and position and noted in especially designed proforma. Results: A total of 158 patients of both gender with mandibular angle fracture of any side were included. Age range in this study was from 25 to 40 years with mean age of $32.689 \pm$ 3.28 years, mean height $1.612 \pm 0.04$ meters, mean BMI $23.929 \pm 2.08 \mathrm{Kg} / \mathrm{m}^{2}$ and mean duration of fracture was $11.354 \pm 6.08$ days. Majority of the patients (55.7\%) belongs to $25-33$ years age groups. While males were $90.5 \%$ as compare to females $9.5 \%$. UnErupted Mandibular third molar was seen in $12.7 \%$ patients, Erupted $44.3 \%$ and Impacted was $43 \%$. Conclusion: Conclusion of this study is that the absence of an impacted third molar decrease the prevalence of mandibular angle fractures.
\end{abstract}

Keywords: Mandibular angle fractures, Mandibular third molar, Frequency.

DOI: $10.7176 / \mathrm{JMPB} / 60-07$

Publication date:October $31^{\text {st }} 2019$

\section{INTRODUCTION}

The mandible is considered the strongest and most rigid bone in facial skeleton, even then it presents a great number of fractures in comparison to other facial Bones.(1). Impacted mandibular teeth are considered as risk factor for the fracture of Nagle of mandible. (2). It has been found in many studies that there is a direct relation between the presence of impacted third molars and a greater likelihood of mandibular angle fractures. (3)it has been found in approximately 50\% of mandibular fractures, teeth are involved.(4). Rajandram RK (5) and his associates has found in a recent study that third molar was $39.6 \%$ absent in patients with mandibular fracture and $60.4 \%$ erupted in patients with mandibular fracture. Inaoka $\mathrm{SD}(6)$ has found that third molar was $11.6 \%$ absent, $46.5 \%$ erupted and $41.9 \%$ impacted in patients with mandibular fracture. No such study has been done before in our local population. Moreover, clinically, the first theory would be related to the presence of partially erupted impacted M3's in which the superficial crown portion of the M3 would create a line of weakness whereas the second theory would focus on deeply impacted M3's. Due to this continued controversy surrounding these two theories, the rational of this study is to determine the frequency of mandibular third molar presence and position in mandibular angle fractures in our general population. Result of this study will generate further evidence on this subject in our local population.

\section{METHODOLOGY}

Patients were included from outdoor department of Oral \& Maxillofacial Surgery, Nishter institute of dentistry Multan From 1st July 2016 to 31st January 2017. Study was started after taking informed consent from the patients and approval of ethical committee. Fracture side was diagnosed by history and examination. Status of mandibular third molar (erupted, un-erupted and impacted) on the side of fracture was evaluated through clinical and radio-graphical examination. Data was collected for basic demographics (Age, Sex and side of fracture).Patients from both gender with age range of 25-40 years having mandibular angle fracture of any side of $<$ one month duration were included in this study. Patients with history of extraction of mandibular third molar and those with history of fracture from gunshot injury were excluded from the study.Data was collected for mandibular third molar presence and position and noted in especially designed proforma. SPSS version 23 was used to determine data variables. Frequency and percentage was computed for age group, gender, side of fracture, 
erupted, un-erupted and impacted third molar. Mean \pm SD was presented for quantitative variables like age, height, BMI and duration of fracture. Effect modifiers like age, duration of fracture, gender, BMI and side of fracture were controlled by stratification. Post stratification chi square test was applied $\mathrm{p} \leq 0.05$ was considered statistically significant.

\section{RESULTS}

Age range in this study was from 25 to 40 years with mean age of $32.689 \pm 3.28$ years, mean height $1.612 \pm 0.04$ meters, mean BMI $23.929 \pm 2.08 \mathrm{Kg} / \mathrm{m}^{2}$ and mean duration of fracture was $11.354 \pm 6.08$ days as shown in TableI. Majority of the patients (55.7\%) belongs to $25-33$ years age groups as shown in Table -II. While males were $90.5 \%$ as compare to females $9.5 \%$ as shown in Table-III.Frequency and percentage of side of fracture is shown in Table-IV. UnErupted Mandibular third molar was seen in $12.7 \%$ patients, Erupted $44.3 \%$ and Impacted was $43 \%$ as shown in Table-V.Stratification of Mandibular third molar presence and position with respect to age, gender, duration of fracture, BMI and side of fracture are shown in Table-VI, VII, VIII, IX and X respectively.

Table-I: Mean \pm SD of patients according to age, height, BMI, duration of fracture.

\begin{tabular}{|c|c|c|}
\hline \multicolumn{2}{|r|}{ Demographics } & Mean \pm SD \\
\hline 1 & Age (years) & $32.689 \pm 3.28$ \\
\hline 2 & Height (meters) & $1.612 \pm 0.04$ \\
\hline 3 & BMI (Kg/m2) & $23.929 \pm 2.08$ \\
\hline & Duration of fracture (days) & $11.354 \pm 6.08$ \\
\hline
\end{tabular}

Table-II: Frequency and percentage of age groups.

\begin{tabular}{|c|c|c|}
\hline \multicolumn{3}{|c|}{$\mathbf{n = 1 5 8}$} \\
\hline Age Groups (years) & $\begin{array}{c}\text { Number of } \\
\text { Patients }\end{array}$ & \%age \\
\hline $\mathbf{2 5 - 3 3}$ & 88 & 55.7 \\
\hline $\mathbf{3 4 - 4 0}$ & 70 & 44.3 \\
\hline Total & $\mathbf{1 5 8}$ & $\mathbf{1 0 0 \%}$ \\
\hline
\end{tabular}

Table-III: Frequency and percentage of gender.

\begin{tabular}{|c|c|c|}
\hline \multicolumn{3}{|c|}{$\mathbf{n = 1 5 8}$} \\
\hline Gender & $\begin{array}{c}\text { Number of } \\
\text { Patients }\end{array}$ & \%age \\
\hline Male & 143 & $90.5 \%$ \\
\hline Female & 15 & $9.5 \%$ \\
\hline Total & $\mathbf{1 5 8}$ & $\mathbf{1 0 0 \%}$ \\
\hline
\end{tabular}

Table-IV: Frequency and percentage of Side of Fracture.

\begin{tabular}{|c|c|c|}
\hline \multicolumn{3}{|c|}{$\mathbf{n = 1 5 8}$} \\
\hline Side of Fracture & $\begin{array}{c}\text { Number of } \\
\text { Patients }\end{array}$ & \%age \\
\hline Left & 110 & $69.6 \%$ \\
\hline Right & 48 & $30.4 \%$ \\
\hline Total & $\mathbf{1 5 8}$ & $\mathbf{1 0 0 \%}$ \\
\hline
\end{tabular}


Table-V: Frequency and percentage of mandibular third molar presence and position.

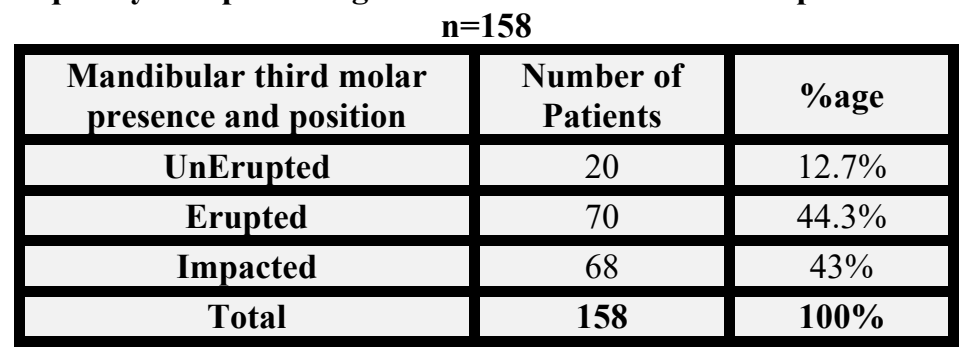

Table-VI: Stratification of mandibular third molar presence and position with respect to age groups.

\begin{tabular}{|c|c|c|c|c|}
\hline \multirow{2}{*}{ Age Groups (years) } & \multicolumn{3}{|c|}{ Mandibular third molar presence and position } & p-value \\
\hline & UnErupted & Erupted & Impacted & \multirow{4}{*}{0.400} \\
\hline $25-33$ & $13(14.8 \%)$ & $41(46.6 \%)$ & $34(38.6 \%)$ & \\
\hline $34-40$ & $7(10 \%)$ & $29(41.4 \%)$ & $34(48.6 \%)$ & \\
\hline Total & $20(12.7 \%)$ & $70(44.3 \%)$ & $68(43 \%)$ & \\
\hline
\end{tabular}

Table-VII: Stratification of mandibular third molar presence and position with respect to gender.

\begin{tabular}{|c|c|c|c|c|}
\hline \multirow{2}{*}{ Gender } & \multicolumn{3}{|c|}{ Mandibular third molar presence and position } & p-value \\
\hline & UnErupted & Erupted & Impacted & \multirow{4}{*}{0.547} \\
\hline Male & $17(11.9 \%)$ & $65(45.5 \%)$ & $61(42.7 \%)$ & \\
\hline Female & $3(20 \%)$ & $5(33.3 \%)$ & $7(46.7 \%)$ & \\
\hline Total & $20(12.7 \%)$ & $70(44.3 \%)$ & $68(43 \%)$ & \\
\hline
\end{tabular}

Table-VIII: Stratification of mandibular third molar presence and position with respect to duration of fracture.

\begin{tabular}{|c|c|c|c|c|}
\hline \multirow{2}{*}{$\begin{array}{l}\text { Duration of fracture } \\
\text { (days) }\end{array}$} & \multicolumn{3}{|c|}{ Mandibular third molar presence and position } & p-value \\
\hline & UnErupted & Erupted & Impacted & \multirow{4}{*}{0.662} \\
\hline $1-15$ & $15(14.2 \%)$ & $45(42.5 \%)$ & $46(43.4 \%)$ & \\
\hline $16-29$ & $5(9.6 \%)$ & $25(48.1 \%)$ & $22(42.3 \%)$ & \\
\hline Total & $20(12.7 \%)$ & $70(44.3 \%)$ & $68(43 \%)$ & \\
\hline
\end{tabular}

Table-IX: Stratification of mandibular third molar presence and position with respect to BMI

\begin{tabular}{|c|c|c|c|c|c|}
\hline & \multirow{2}{*}{ BMI $\left(\mathrm{Kg} / \mathrm{m}^{2}\right)$} & \multicolumn{3}{|c|}{ Mandibular third molar presence and position } & p-value \\
\hline & & UnErupted & Erupted & Impacted & \multirow{4}{*}{0.800} \\
\hline 1 & $\leq 25$ & $17(13.2 \%)$ & $58(45 \%)$ & $54(41.9 \%)$ & \\
\hline 2 & $>25$ & $3(10.3 \%)$ & $12(41.4 \%)$ & $14(48.3 \%)$ & \\
\hline & Total & $20(12.7 \%)$ & $70(44.3 \%)$ & $68(43 \%)$ & \\
\hline
\end{tabular}

Table-X: Stratification of mandibular third molar presence and position with respect to side of fracture.

\begin{tabular}{|c|c|c|c|c|}
\hline \multirow{2}{*}{ Side of Fracture } & \multicolumn{2}{c|}{ Mandibular third molar presence and position } & p-value \\
\cline { 2 - 5 } & UnErupted & Erupted & Impacted & \\
\hline $\mathbf{1}$ & Left & $14(12.7 \%)$ & $54(49.1 \%)$ & $42(38.2 \%)$ \\
\hline $\mathbf{2}$ & Right & $6(12.5 \%)$ & $16(33.3 \%)$ & $26(54.2 \%)$ \\
\hline
\end{tabular}

\section{DISCUSSION}

There is a variable greater risk of mandibular, angle fracture depending upon the position of mandibular third molar. (7). Also In agreement with Halmos et al. ${ }^{8}$ the results of this study confirm the greater risk of angle fractures when the third molar is present. However, Iida et al. ${ }^{9}$ did not observe any significant difference between the position of the third molar and the risk of angle fractures. Males are more exposed to the risk factors for facial 
trauma, such as road accidents and physical aggression that's why there is greater predisposition in males. With regards to the localization of the associated fractures in the angle fractures, there was a predominance, in this study, of the mandibular body region, followed by the symphysis/parasymphysis, which were on the opposite side of the angle fracture. This study confirms that of Lee et al. ${ }^{10}$ which states that the presence of a third molar (erupted or impacted) increases the risk of angle fractures. The hypothesis proposed by Reitzik et al. ${ }^{11}$ tries to explain the third molar as risk factor, reporting that the bone space occupied by the tooth makes the mandibular angle more fragile. Thus, according to this theory, the deeper localization of the tooth would increase this risk. However, the results of this study are at odds with this. Meisami et al. ${ }^{12}$ suggests that mandibular resistance is maintained by the integrity of the cortical bone, not the medullary bone, which means that the superficial position of the third molar breaks the integrity of external oblique line, creating a fragile point in the mandible. Fuselier et al. ${ }^{13}$ also made a study with a sample of 1210 patients, which concluded that the deeper localization of the third molar is not related to an increase in the risk of angle fracture, which is in agreement with Meisami et al. ${ }^{12}$ According to Kober et al. ${ }^{14}$ when the third molar is erupted or absent, the resistance of the mandibular angle increases, causing the force to be transmitted to a more fragile region, namely the condyle. According to Ellis, ${ }^{15}$ the difficulties of reduction and fixation are more frequent in the treatment of fractures, due to less visibility in the operative field, a difficult hemostasia and the possibility of facial nerve injury. ${ }^{16-18}$

\section{CONCLUSION}

Conclusion of the study is that the absence of an impacted third molar decrease the prevalence of mandibular angle fractures.

\section{REFERENCES}

1. Nogami S, Yamauchi K, Yamashita T, Kataoka Y, Hirayama B, Tanaka K, et al. Elderly patients with maxillofacial trauma: study of mandibular condyle fractures. Dent Traumatol. 2015 Feb;31(1):73-6.

2. Subbaiah MT, Ponnuswamy IA,David MP. Relationship between mandibular angle fracture and state of eruption of mandibular third molar:A digital radiographic study. J Indian Acad Oral Med Radiol. 2015;27:35-41.

3. Safdar N, Meechan JG. Relationship between fractures of the mandibular angle and the presence and state of eruption of the lower third molar. Oral Surg Oral Med Oral Pathol Oral Radiol Endod. 1995;79:680-4.

4. Kumar PP, Sridhar BS, Palle R, Singh N, Singamaneni VK, Rajesh P. Prognosis of teeth in the line of mandibular fractures. J Pharm Bioallied Sci. 2014 Jul;6(Suppl 1):S97-S100.

5.Rajandram RK, Nabil S, Shareif MS, Ishak I, Marhazlinda J, Nordin R, et al. Mandibular third molar and angle of mandible fractures: an unsolved clinical dilemma. Sains Malaysiana. 2013;42(1):39-43.

6.Inaoka SD, Carneiro SCAS, Vasconcelos BCE, Leal J, Porto GG. Relationship between mandibular fracture and impacted lower third molar. Med Oral Patol Oral Cir Bucal. 2009 Jul 1;14(7):E349-54.

7. Peterson LJ, Ellis E, Hupp JR, Tucker MR. Cirurgia oral e maxillofacial contemporânea. 3a ed. Rio de Janeiro: Guanabara Koogan; 2000.

8. Halmos DR, Ellis E 3rd, Dodson TB. Mandibular third molars and angle fractures. J Oral Maxillofac Surg. 2004;62:1076-81.

9. Iida S, Nomura K, Okura M, Kogo M. Influence of the incompletely erupted lower third molar on mandibular angle and condylar fractures. J Trauma. 2004;57:613-7.

10. Lee JT, Dodson TB. The effect of mandibular third molar presence and position on the risk of an angle fracture. J Oral Maxillofac Surg. 2000;58:394-8.

11.Reitzik M, Lownie JF, Cleaton-jones P, Austin J. Experimental fractures of monkey mandibles. Int J Oral Surg. 1978;7:100-3.

12. Meisami T, Sojat A, Sàndor GK, Lawrence HP, Clokie CM. Impacted third molars and risk of angle fracture. Int J Oral Maxillofac Surg. 2002;31:140-4.

13. Fuselier JC, Ellis EE 3rd, Dodson TB. Do mandibular third molars alter the risk of angle fracture? J Oral Maxillofac Surg. 2002;60:514-8.

14. Kober C, Sader R, Thiele H, Bauer HJ, Zeilhofer HF, Hoffmann KH, et al. Stress analysis of the human mandible in standard trauma situations with numerical simulation. Mund Kiefer Gesichtschir. 2001;5:114-9.

15. Ellis E 3rd. Complications of mandibular condyle fractures. Int J Oral Maxillofac Surg. 1998;27:255-7.

16. Hendrix JH Jr, Sanders SG, Green B. Open reduction of mandibular condyle; a clinical and experimental study. Plast Reconstr Surg Transplant Bull. 1959;23:283-7.

17. Peters RA, Caldwell JB, Olsen TW. A technique for open reduction of subcondylar fractures. Oral Surg Oral Med Oral Pathol.1976;41:273-80.

18. Brown AE, Obeid G. A simplified method for the internal fixation of fractures of the mandibular condyle. Br J Oral Maxillofac Surg. 1984;22:145-50. 